\title{
Detecting Market Power Along Food Supply Chains: Evidence and Methodological Insights from the Fluid Milk Sector in Italy
}

\author{
Daniele Cavicchioli $\mathbb{D}$ \\ Department of Environmental Science and Policy (ESP), Università degli Studi di Milano, Via Celoria, 2, \\ 20133 Milano, Italy; daniele.cavicchioli@unimi.it; Tel.: +39-025-031-6468
}

Received: 26 October 2018; Accepted: 30 November 2018; Published: 5 December 2018

\begin{abstract}
Concerns about the functioning of food supply chains have been raised by the European Commission over past years, calling for more effective and coordinated action by National Competition Authorities (NCAs). To fill this knowledge gap, an equilibrium displacement model is used to screen conduct along the supply chain, combining the advantages of asymmetric price transmission (APT) studies and structural models. The test was carried out on the Italian fluid milk supply chain following market monitoring action by the NCA. Three periods (1996-2003; 2000-2008 and 1996-2008) have been examined, finding imperfect competition over 1996-2008 and 2000-2008, while no conclusions may be drawn over the time span 1996-2003. In the testing process, the model's peculiarities and certain limitations emerged, and related suggestions for its improvement are discussed. This approach may be used as a preliminary "fast" test for competition policy screening, as a complement to other methodologies. However, further theoretical and empirical model validation is necessary.
\end{abstract}

Keywords: conduct screening; oligopoly; oligopsony; price transmission; vertically related markets

\section{Introduction}

The food industry and food retailing have witnessed a continuous process of concentration in many European countries over the last few decades [1], and this phenomenon has raised concerns among public authorities and governments regarding potential anti-competitive behaviours along food supply chains. Such issues result from, amongst other sources, oligopolistic and oligopsonistic power, which may be exerted within agrifood systems at food processing and at retailing stages to the detriment of farmers (suppliers of raw agricultural inputs) and consumers [2-4]. For these reasons, a vast amount of research has been carried out by agricultural (and non-agricultural) economists to analyse anti-competitive behaviours in agrifood markets using different methodological approaches that can roughly be classified into two broad categories: asymmetric price transmission (APT) studies and new empirical industrial organization (NEIO) models.

Following the suggestion provided by Digal and Ahmadi-Esfahani [5] on market power analysis in food retailing, and taking into account recent considerations of Lloyd [6] on price transmission analysis, the aim of this paper is to identify and apply a methodology able to combine the advantages of the aforementioned approaches to test conclusively for the exertion of market power along the whole food supply chain using easily available data. What seems to be the more appropriate theoretical background for this purpose began with McCorriston et al. [7,8] and was then developed and adapted by Lloyd et al. [9-11] with empirical application to some food supply chains in the UK (hereinafter referred to as the McCorriston-Lloyd approach). It is worth highlighting that on the competition policy side, such a "supply chain approach" would be particularly useful in the light 
of the Communication from the European Commission "A better functioning food supply chain in Europe" [12,13], which calls, inter alia, for more effective and coordinated action by NCAs. This work applies the McCorriston-Lloyd approach to the Italian fluid milk supply chain over three time periods (1996-2003; 2000-2008 and 1996-2008) following market monitoring action by the NCA [14]. The empirical implementation of the model provides evidence of its peculiarities and limitations, based on which indications for model testing and improvements are suggested.

The remainder of the paper is organized as follows. The second section, the literature review, provides a brief treatment of existing methodologies for the analysis of imperfect competition in food chains, highlighting their strengths and weaknesses and providing a rationale for using the theoretical model adopted. The following section describes the McCorriston-Lloyd approach, representing the reference framework for the empirical analysis. The next section describes the construction of the dataset and time series stationarity tests. The econometric strategy employed in the empirical analysis and consequent results are presented. The final section draws the main conclusions and provides suggestions for future research.

\section{Literature Review}

This section gives a brief illustration of the principal approaches adopted to examine the presence and the extent of imperfect competition at different levels of analysis. In line with previous studies [5], the main objective is to highlight the advantages and disadvantages of each group of methodologies rather than giving an exhaustive review of the relevant literature. The end of the section summarizes and compares the focal features of each approach, pointing to the McCorriston-Lloyd approach as a unifying framework to examine market power along food chains. The discussion of asymmetric price transmission (APT) studies draws heavily on the survey by Meyer and von Cramon-Taubadel [15], taking into account the suggestions provided by Lloyd [6], whereas that on new empirical industrial organization (NEIO) structural models takes as its reference point the contribution of Perloff et al. [16].

\subsection{Asymmetric Price Transmission (APT) Studies}

Economic theory recognizes in the price mechanism a key role for carrying signals among economic agents about the relative scarcity of goods and factors in a certain market to ensure an efficient allocation of resources. It is also of paramount importance that price signals are correctly transmitted among markets related horizontally (same good or factor in different places or countries) and vertically (a good in a market is a factor in the subsequent one). An incorrect or incomplete transmission of prices in vertically related markets may give rise to a double concern, both for academics and consumers. On the one hand, imperfect price transmission may represent an inconsistency for economic theory, as shown by the exhaustive empirical work carried out by Peltzman [17], while on the other hand, it is often considered as evidence of anti-competitive behaviour, and, sometimes, it has been employed in comparison with Antitrust intervention on anti-competitive practices along the agri-food chain [18]. For this reason, a remarkable amount of work has been done on this topic, with particular reference to vertically related markets such as food supply chains.

For the most part, these studies look for asymmetries between input (farm) and output (consumer) price movements in vertically related markets; in this context, there is asymmetry when an increase (decrease) in an input price is fully passed on to the output price, while a decline (rise) in the former is transmitted incompletely to the latter. Asymmetries can be classified according to the nature of incomplete transmission [15] —in the rapidity or size of the price adjustment-and the direction of asymmetry [17]. According to the second criterion, there is positive APT when (assuming causality from input to output prices) food prices adjust incompletely to farm price increases (positive variation) rather than to their fall. In the reverse case, negative APT takes place when the imperfect transmission from input to output price pertains only to decreases in farm prices (negative variation). Empirical analyses on price dynamics along food chains may differ according to the degree of homogeneity or differentiation of the product based, for instance, on quality certification [19]. Considering the 
marketing margin $[20,21]$ as the difference between output and input prices, and taking into account that exogenous shocks may reverse the causality pricing so far assumed (flowing from farm to food prices), a more general and appropriate definition would be that positive APT allows for a complete transmission of margin-reducing price movements, whereas negative APT happens when margin-stretching price signals are fully passed through the marketing chain [15].

What is more important for competition policy purposes is to establish unambiguously what causes ATP in vertical marketing chains; in spite of the vast amount of work done on the topic, different determinants are suggested by many authors, without a reference framework able to unify contrasting explanations [22]. Market power exertion in one or more intermediate stages of the food marketing chain is pointed to as a cause of APT [22-27] to the detriment of suppliers of raw agricultural products and food consumers. However, the causal relationship between imperfect competition and APT is not theoretically grounded [5,22,28,29]. According to Meyer and von Cramon-Taubadel [15], testing this kind of relationship is not easily feasible as it would require meta-analysis using evidence from previous studies on different supply chains in different countries to capture the treatment effect of imperfect competition on price transmission. In any case, the lack of homogeneity among the econometric techniques employed in each piece of empirical research would mean that the data and results would not be comparable. The only empirical work that overcomes such limitations is that by Peltzman [17], which analysed price transmission in a wide range of vertically related markets using the same econometric methodology. However, in this case, market power exertion in each vertical chain was proxied using a market concentration index (Hirschman-Herfindahl) to gather cross-sectional evidence on the effect of imperfect competition on APT. Such an approach relies on the structure-conduct-performance paradigm which has been criticized as it assumes a one-way relationship from structure to performance and does not take into account simultaneity bias and the endogeneity of market structure [30-32]. On the same premise, Bakucs et al. [33] undertook a meta-analysis of the relationship between price transmission and market structure in agro-food markets, recognizing that concentration measures approximate only the potential for the exertion of market power and not actual conduct. It seems, once again, that the causation of APT by imperfect competition cannot reliably be tested. On the theoretical side, Gardner [20] developed a farm-retail supply chain equilibrium displacement model, assuming perfect competition in the intermediate stage and constant returns to scale; the model indicates a higher effect of food demand shifters compared to farm supply shifters on the marketing margin. Using numerical simulations based on the same model, Kinnukan and Forker [23] found that the elasticity of price transmission differs according to the side of the shift, suggesting that this could lead to APT. This would mean that APT can take place without imperfect competition in the intermediate stages of the supply chain, even if von Cramon-Taubadel [34] suggests that in this context APT would only be apparent. Following the Gardner framework, McCorriston et al. [7,8] and Weldegebriel [35] have shown that imperfect competition can reduce price transmission elasticity, but different conditions in the elasticity of substitution and returns to scale may either amplify or offset the market power effect. This implies that if processing and retailing markets are imperfectly competitive but show high elasticity of substitution and increasing returns to scale, such technology and cost conditions can compensate for the market power effect, yielding symmetric price transmission along the marketing chain. In this case, the presence of APT would not be a viable tool for detecting the exertion of market power along food chains.

In addition to the aforementioned criticisms of the market power-APT hypothesis, other causes of asymmetric adjustment of price movements are found in the literature, such as menu-repricing costs [17,36-39]; inventory costs, especially at the retail level [40]; inflation [41]; and policy intervention in farm prices in the US [23] and in Europe [42,43]. Even if some of these causes may lead to short-term APT, it would be harmless for social welfare [15], giving rise to the idea that imperfect competition cannot be the only determinant of APT.

To summarize what has been reported so far, the APT approach presents the advantage of using easily available data on farm and consumer price movements to examine and gain insights into the 
dynamics of the whole food supply chain. In doing so, all the vertically related stages within the marketing (farming, processing, wholesaling and retailing) chain are analysed. However, for a number of theoretical and empirical reasons, the presence of APT cannot represent conclusive evidence of market power exertion in one or more stages of the marketing chain analysed.

\subsection{New Empirical Industrial Organization (NEIO) Structural Models}

The broad category of new empirical industrial organization (NEIO) models was born as a consequence of dissatisfaction with the structure-conduct-performance paradigm (Sheldon and Sperling 2003). In their simpler versions, NEIO models are usually aimed at testing for the presence of market power exertion or to estimate its extent at the market level and not along the entire food chain; they differ according to the side of the market analysed (product supply or factor demand, measuring, respectively, oligopolistic or oligopsonistic power), the kind of product examined (homogeneous vs. differentiated), the estimation strategy adopted (parametric vs non-parametric model), and the repetition of interactions among economic agents (static vs. dynamic models).

For clarity (and to provide a better explanation of the theoretical approach adopted later), oligopolistic power in a static, parametric and homogeneous product setting is exerted when sellers increase product prices above the marginal cost (MC). Unfortunately, firms' marginal costs are difficult to observe but can be estimated by exploiting the different revenue functions of firms under different market structures. In fact, under perfect competition, a firm's selling price $(\mathrm{P})$ equals its marginal revenue (MR), whereas under monopoly, the single seller represents the entire market supply and therefore its marginal revenue decreases as the product quantity $(Q)$ increases: $M R=P+Q(d P / d Q)$, where $\mathrm{dP} / \mathrm{dQ}$ is the amount of price decrease for an additional unit of product sold on the market. Both the previous expressions can be generalized in a single revenue function: $M R=P+\theta Q(d P / d Q)$, where $\theta$ represents a conduct parameter, ranging from 0 to 1 , measuring the extent of oligopolistic power. There is perfect competition when $\theta=0$ or monopoly when $\theta=1$; more generally, $\theta>0$ indicates the exertion of oligopolistic power (note that a symmetric explanation may be provided for oligopsonistic power exerted on the demand side for raw agricultural products). In empirical terms, $\theta$ and the marginal cost are estimated using a simultaneous equation model composed of optimality conditions (by equating MR and MC functions) and the market demand function [16]. To set up such a model, data on product price and quantity, demand shifters (i.e., consumer income, price of substitutes) and supply shifters (i.e., factor prices) are needed. Note that such a procedure allows estimation of the degree of market power only on one side (supply) of one stage within a supply chain.

In their more complex versions, NEIO models analyse the extent of oligopolistic and oligopsonistic power on more stages of the marketing chain [44,45], estimating market power for each stage of the supply chain, but presumably at the cost of increasing demand for data and econometric sophistication. Another notable recent development pertains to the contribution of Grau and Hockmann [46], that starting from a NEIO model, developed a set of two price equations in order to test successive oligopsony power in the German dairy chain

As NEIO models are rooted in economic theory, findings on the extent of market power exertion derived from their use are more conclusive and reliable than those of APT studies [28] even if there are some criticisms regarding their accuracy [47]; however, their requirements in terms of the quantity and quality of data and econometric efforts increase with model complexity (single stage vs. multi-stage).

The two groups of models (APT and NEIO) share in some way the same objective-to test or estimate market power exertion, even if the results of APT models are not conclusive- but they operate at different levels, use different kinds of data and provide different findings; to make the detection of market power exertion in agrifood systems more effective for competition policy purposes, it is desirable to integrate such approaches [5]. As previously stated, such an objective requires a methodology that unifies the advantages and addresses the limitations of APT and NEIO models to test conclusively the exertion of market power along the whole food supply chain. The search for such a methodology should begin from the first model, describing explicitly the functioning of a vertically 
related supply chain [20], even if assuming perfect competition in the intermediate stage. McCorriston and others $[7,8]$ adapted the model, allowing for market power exertion within the marketing chain, variable elasticity of substitution and non-constant returns to scale to derive the elasticity of price transmission under different conditions. Lloyd and others [9-11] built on this framework, developing (and applying) a theoretical model able to detect market power exertion along the food chain.

Such contributions are not unique; indeed, Reference [48] (and successively also Fulton and Tang [49]), following Wohlgenant [50], modified the Gardner model, relaxing the assumption of perfectly competitive behaviour to test the effect on the farm-retail price spread (and then to check for market power exertion). Both of the approaches use conduct parameters to allow for imperfect competition along the food chain, but only the latter explicitly considers the entrance of new firms. However, the method used by Holloway [48] is more demanding in terms of data for the empirical application, as it requires time series data for prices and quantities (of raw agricultural products), whereas the McCorriston-Lloyd model needs time series of prices (or price indices) supplemented by other easily available data (proxies of marketing costs, demand and supply shifters). From the perspective of data requirements, the latter approach is preferable when data on product quantities are not easily available. Perhaps for this reason, such a methodology has been employed in many countries [27,51-57]. Recently, Kinnucan and Tadjon [58] developed a framework to test for perfect competition, claiming its advantages against that of Lloyd et al. [11]. Unfortunately, this approach requires farm and retail absolute prices, while often only index prices are available in many countries. In this context, the framework developed by Grau and Hockmann [46] may be considered a useful integration into the "first-pass" test used in the present contribution. The present paper contributes to the current literature by checking for the presence of imperfect competition in the Italian fluid milk chain, applying the McCoriston-Lloyd model over a time span posterior to the market monitoring action by the NCA.

\section{Theoretical Model}

The McCorriston-Lloyd model used for the analysis is a modification of the Gardner [20] equilibrium displacement model; whereas Gardner considered the effect of various shifters (farm input supply and food retail demand) on the farm-retail price spread (difference between retail price and farm-gate price), assuming perfectly competitive markets, the framework presented here relaxes this assumption and allows for imperfect competition along the food chain, introducing two conduct parameters of oligopolistic and oligopsonistic power. In doing so, a reduced form equation is derived to test for the presence (and not to measure the extent) of imperfect competition along the food chain; in the equation, the variable affecting the marketing margin differs according to the values of the conduct parameters or, in other words, according to the presence of anti-competitive behaviors along the food supply chain. For simplicity, in this paper the intermediate stage of the food chain is considered as an aggregate of the food processing and retailing sectors. For the sake of brevity, the full derivation of the theoretical model is presented in Appendix B.

The following equation describes how various exogenous shocks affect the marketing margin in the presence of perfect competition or when market power is exerted along the food chain:

$$
P_{x}-P_{a}=\frac{D\left(\frac{\theta}{b}+g \mu\right)+(1+b g)(y+z E)+\left(\frac{\theta}{b}+g \mu\right) c N-(\theta+b g \mu)(h+g W)}{(1+\theta)+b g(1+\mu)}
$$

where $P_{x}$ is the retail price, $P_{a}$ is the farm gate price of the agricultural product, and their difference is the price spread (or marketing margin). The equation accounts for the various parameters of the retail demand function $(D, b, c)$ and of the supply function of the agricultural product $(h, g)$. Attention is paid to the exogenous shifters, both on the demand side $(N)$ and on the supply side $(W)$, that may displace market equilibria. The equation accounts also for the non-agricultural marketing costs of transport, processing and retailing. Such costs have a fixed component $(y)$ and a variable component $(z E)$. To test the exertion of market power along the chain (whatever is the stage in which it is exerted) 
the equation embodies an oligopolistic $(\theta)$ and oligopsonistic $(\mu)$ conduct parameter. When both parameters are equal to zero, the food supply chain is perfectly competitive, while if $\theta$ or $\mu$ are different from zero, the market power is exerted at some intermediate stage of the chain. In this framework, such parameters (and then the competitive behavior) are not directly observed, but are inferred by the effect of marketing costs and exogenous shifters on the marketing margin.

Note that if the intermediate stage of the supply chain exerts neither oligopolistic $(\theta=0)$ nor oligopsonistic power $(\mu=0)$, Equation (1) collapses into a simpler form, representing the marketing margin under perfect competition:

$$
P_{x}-P_{a}=y+z E=M
$$

Based on the model findings, two important points can be made; first, under perfect competition along the food chain, the price spread $\left(P_{x}-P_{a}\right)$ is represented only by marketing costs $(M)$ and second, it is not affected by shifts in the farm supply $(W)$ and consumer demand $(N)$ functions. However, if oligopolistic or oligopsonistic power is exerted along the food chain (i.e., if $\theta$ or $\mu$ differ from zero), both of the exogenous shifters ( $W$ and $N$ ) affect the magnitude of the price spread. In particular, under anticompetitive behaviour, a shift in consumer demand $(N)$ increases the margin, whereas a shift in farm supply $(W)$ reduces it. Note that if market power is exerted within the food chain, both of the shifters affect the margin simultaneously. The effect of the exogenous shifter on the marketing margin is then "activated" by the exertion of oligopolistic or oligopsonistic power in the intermediate stage of the chain.

Based on (1) and (2), we use the following unrestricted equation (including the exogenous variables $W$ and $N$ ) to test two different (null) hypotheses of perfect competition or of market power exertion:

$$
P_{x}=\beta_{0}+\beta_{1} P_{a}+y \beta_{2} M+\beta_{3} N+\beta_{4} W
$$

Under perfect competition along the food chain $(\theta=\mu=0)$, none of the shifters affect the margin and the associated parameters are expected to not differ much from zero. An additional prerequisite, consistent with economic theory and with Equations (1) and (2), is that the retail price has to be positively related to both the producer price $\left(\beta_{1}>0\right)$ and marketing cost $\left(\beta_{2}>0\right)$ in the long term, and the associated parameter estimates should be positive and statistically significant. Thus, perfect competition can be tested as follows:

$$
H_{0 p c}: \beta_{1} \succ 0 ; \beta_{2} \succ 0 ; \beta_{3}=\beta_{4}=0
$$

Note that whereas by failing to reject the null hypothesis we can conclude that the supply chain is perfectly competitive, rejection of the null hypothesis is not a sufficient condition to deduce the exertion of market power (although in conventional hypothesis testing, this would be the case). To reach such a conclusion, some additional conditions are required; first, both of the parameters have to be significantly different from zero $\left(\beta_{3} \neq 0 ; \beta_{4} \neq 0\right)$, and second, the parameter of exogenous shifter $\mathrm{N}$ has to be positive $\left(\beta_{3}>0\right)$ while the parameter of $\mathrm{W}$ has to be negative $\left(\beta_{4}<0\right)$. Similarly, market power exertion along the food chain is tested under a different null hypothesis:

$$
H_{0 m p}: \beta_{1} \succ 0, \beta_{2} \succ 0 ; \beta_{3} \succ 0 ; \beta_{4} \prec 0
$$

In the interpretation here (which differs slightly from the version of the authors who developed and implemented the model), only empirical results failing to reject $H 0_{p c}$ (perfect competition) or $\mathrm{HO}_{\mathrm{mp}}$ (market power exertion) can be considered plausible and conclusive. Alternative hypotheses (only one of the shifters significant and/or not signed according model prescriptions) would yield ambiguous and inconclusive results. 


\section{Data and Methodology}

The Italian fluid milk supply chain was screened for the exertion of market power; in addition to following up the market monitoring action by the NCA [14], the choice was also made to provide a better fit with model restrictions (input-output coefficient equal to one). In what follows, the first subsection describes the dataset and the second treats the tests carried out on each time series.

\subsection{Description of Dataset}

To apply the theoretical model, 29 time series were used within three different datasets (called respectively A, B and AB), covering partially or totally overlapped time periods (January 1996 to October 2003 for database A; January 2000 to October 2008 for database B; January 1996 to October 2008 for database $\mathrm{AB}$ ) using monthly data from publicly-available national data sources: Istat, Conistat, Coeweb and Ismea. All the data are made available in index form (in each time series, all the values have been divided for the average value of a base year-1995 or 2000 - and then multiplied by 100) and refer to the retail milk price; the producer milk price (also proxied by producer animal price and producer import milk price indices); the index of wages in dairy processing (as a proxy of marketing costs); retail price indices for all goods, food, food and alcoholic beverages (as a proxy of demand shifters); and the farm input price index (as a proxy of the farm supply shifter). The names of the variables, abbreviations, sources and manipulations are reported in Table 1, while Appendix A reports summary statistics for each dataset (Tables A1-A3).

Some concerns may be raised regarding the use of producer and retail price indices from different statistical sources (Istat and Ismea respectively) or approximating the producer price using the index of a broader category (animal products). Unfortunately, the available data are not homogeneous (producers and retail price indices) either in terms of statistical source or level of aggregation; to exploit all the available statistical information where possible, the original time series have been lengthened by rescaling the missing period of the same series with another basis. This operation was performed extending those time series with both of the base indices (1995 = 100 and $2000=100)$ using one or more overlapping period between two series for the same variable (for instance producer milk price based on 1995 and 2000). In particular, the choice was made to maximize the number of rebased series where possible to increase the probability of finding a combination of variables fitting both model requirements (see end of previous section) and the restrictions imposed by the econometric estimation strategy (see next section on Error Correction Model). Clearly, the extensive use of rescaled time series allows for the examination of a longer period, but it may give rise to concerns about the impact of data manipulations on the reliability of empirical results.

In other words, rescaled time series contain non-genuine information in their rebased parts. To find a balance between such points, the adopted strategy was to separate the variables into two "genuine" datasets (A and B) containing mainly non-rebased variables and confining rebased time series to another (longer) dataset $(\mathrm{AB})$ : rebased variables are denoted by the last letter that indicates their basis (A for 1995 and B for 2000), preceded by a number indicating the overlapping period used for the rebasing (from 1 to 5), while "genuine" (non-rescaled time series) are denoted only by the letter that identifies their basis. Demand and supply shifter variables are exceptions to the aforementioned rules. 
Table 1. Variables description and data sources.

\begin{tabular}{|c|c|c|c|c|c|c|}
\hline Variable & Abbrev & Data Description & Source & Base Year $=100$ & Period & Elaborations \\
\hline Retail Milk price & RM1 & Consumer Price Index: milk & Istat & 1995 & $96.1-09.3$ & genuine data \\
\hline Produc. Milk Price & PMA & Producer Price Index: cow milk & Ismea & 1995 & $95.1-03.10$ & genuine data \\
\hline Produc. Milk Price & PMB & Producer Price Index: cow milk & Ismea & 2000 & $00.1-09.2$ & genuine data \\
\hline Produc. Milk Price & PM1A & Producer Price Index: cow milk_-rescaled & Ismea & 1995 & $95.1-09.2$ & rescal 00.1-03.10 \\
\hline Produc. Milk Price & PM2A & Producer Price Index: cow milk—rescaled & Ismea & 1995 & $95.1-09.2$ & rescal 00.1-00.12 \\
\hline Produc. Milk Price & PM3A & Producer Price Index: cow milk-rescaled & Ismea & 1995 & $95.1-09.2$ & rescal 01.1-01.12 \\
\hline Produc. Milk Price & PM4A & Producer Price Index: cow milk—rescaled & Ismea & 1995 & $95.1-09.2$ & rescal 02.1-02.12 \\
\hline Produc. Milk Price & PM5A & Producer Price Index: cow milk—rescaled & Ismea & 1995 & $95.1-09.2$ & rescal 03.1- 03.10 \\
\hline Produc. Milk Price & PM1B & Producer Price Index: cow milk_-rescaled & Ismea & 2000 & $95.1-09.2$ & rescal 00.1-03.10 \\
\hline Produc. Milk Price & PM3B & Producer Price Index: cow milk-rescaled & Ismea & 2000 & $95.1-09.2$ & rescal 01.1-01.12 \\
\hline Produc. Milk Price & PM4B & Producer Price Index: cow milk_rescaled & Ismea & 2000 & $95.1-09.2$ & rescal 02.1-02.12 \\
\hline Produc. Milk Price & PM5B & Producer Price Index: cow milk—rescaled & Ismea & 2000 & $95.1-09.2$ & rescal 03.1-03.10 \\
\hline Produc. Anim Price & PAPA & Producer price Index: animal products & Istat & 1995 & $95.1-04.12$ & genuine data \\
\hline Produc. Anim Price & PAP1A & Produc. Pric. Ind.: animal products-rebas & Istat & 1995 & $95.1-08.12$ & rescal 04.1-04.12 \\
\hline Produc. Anim Price & PAPB & Producer price Index — animal products & Istat & 2000 & $00.1-08.12$ & genuine data \\
\hline Produc. Anim Price & PAP1B & Produc. price Index: anim products, rebas & Istat & 2000 & $95.1-08.12$ & rescal 04.1-04.12 \\
\hline Import Produc. Milk & IPMA & Index of milk import price from EU 25 & Coeweb & 1995 & $93.1-09.3$ & Indexed price $€ / \mathrm{kg}$ \\
\hline Import Produc. Milk & IPMB & Index of milk import price from EU 25 & Coeweb & 2000 & $93.1-09.3$ & Indexed price $€ / \mathrm{kg}$ \\
\hline Marketing Shifter & MA & Index of wages, dairy processing sector & Conistat & 1995 & $96.1-02.12$ & genuine data \\
\hline Demand Shifter & DS1 & Consumer Price Index: general index & Istat & 1995 & $96.1-09.03$ & genuine data \\
\hline Demand Shifter & DS2 & Consumer Price Ind: general index-no tobacco & Istat & 1995 & $96.1-09.3$ & genuine data \\
\hline Demand Shifter & DS3 & Consumer Price Index: food, wines and spirits & Istat & 1995 & $96.1-09.3$ & genuine data \\
\hline Supply Shifter & SS1 & producer price index for dairy farms & Ismea & 1998 & $94.1-08.10$ & Correc techn progr \\
\hline Supply Shifter & SS2 & producer price index for dairy farms & Ismea & 1995 & $94.1-08.10$ & Correc techn progr \\
\hline Supply Shifter & SS3 & producer price index for dairy farms & Ismea & 1995 & $94.1-06.1$ & genuine data \\
\hline Supply Shifter & SS4 & producer price index for dairy farms & Ismea & 2000 & $00.1-08.10$ & genuine data \\
\hline
\end{tabular}




\subsection{Time Series Stationarity Tests}

The use of time series for the empirical analysis requires some preliminary tests on their properties; Equation (3) cannot be estimated using ordinary least squares (OLS) regression unless all the time series used are stationary $[22,59,60]$, that is, having constant statistical properties (mean, variance and covariance). According to Granger and Newbold [61], an OLS regression with non-stationary variables leads to unreliable estimates, resulting in spurious regression. A stationary variable is said to be integrated of order zero, $\mathrm{I}(0)$; when a nonstationary variable became stationary after differencing (subtracting from each value $x t$ the previous value, $x t-1$ ), it contains a unit root, or is integrated of order one, I(1). Thus, the test for the exertion of market power using OLS regression requires that all the time series used are stationary in level; if this condition is not satisfied, other estimation procedures should be used, provided that all the variables employed are I(1). To fulfil these requirements, all the time series in each dataset were tested for stationarity in level and in first differences looking for their order of integration. Stationarity was tested using the augmented Dickey-Fuller (ADF) test [62] and the Phillips-Perron (PP) test [63] which takes nonstationarity (presence of a unit root) as the null hypothesis against the alternative of stationarity. Furthermore, variables in level and first differences were also tested using the Kwiatkowski-Phillips-Schmidt-Shin (KPSS) test [64], which assumes stationarity as the null hypothesis against non-stationarity as the alternative hypothesis. Results of stationarity tests for all the variables (both in level and in firs difference) of each dataset are available in Supplementary Materials. In each test, an underlying data-generating process was assumed with the variable having, respectively, intercept and time trend and intercept only. Judgments about the order of integration of each variable were made comparing t-statistics (for ADF), adjusted t-statistics (for PP) and Lagrange multiplier statistics (for KPSS) with critical values for each distribution (at 1\%, 5\% and $10 \%$ ). For the ADF and PP tests, the estimation output also provided probabilities of unit roots. As results can differ among the tests and can be sensitive to functional form specification (intercept with or without trend), the decision was made to consider stationary in level those variables with low probability $(p<5 \%)$ of acceptance of the null hypothesis in at least one specification of the ADF and PP tests, and at the same time a probability greater than $5 \%$ of accepting the null hypothesis in both of the KPSS test specifications. Stationarity tests were performed separately on the three datasets as the results could change according to time series length. According to the stated criteria, all the variables in dataset A (January 1996 to October 2003) are nonstationary in level (except for import milk price IPMA) and stationary in first difference; all the variables in dataset B (January 2000 to October 2008) are I(1) in level and I(0) in first difference; while all variables in the period covered by dataset AB (January 1996 to October 2008) have a unit root in level (except for IPMA and IPMB) and are stationary in first difference. The full results of the unit root tests are available upon request. This confirms, as suspected, that OLS estimation is not a viable tool to perform the market power test; however, as almost all variables have the same order of integration, I(1), another econometric strategy can be followed to detect for imperfect competition along the fluid milk chain.

\subsection{Estimation Strategy}

Giving the non-stationarity of time series, estimation strategies other than OLS regression have to be used to avoid spurious results. According to the Engle and Granger [65] representation theorem, if a set of nonstationary variables share the same order of integration, there may be a variable constructed by difference or linear combination that is stationary. If such a condition holds, the variables are said to be cointegrated and they share a long-term relationship, whereas differences between them are short-term errors. When some variables are cointegrated, an error correction model (ECM) can be estimated, establishing a relationship between changes in one variable of the set (for our purposes the dependent variable) with respect to long-term equilibrium with the other variables in the set. The ECM splits such changes (errors) in a short-term component, which causes a departure from the long-term equilibrium, and a long-term component, called the error correction term (ECT), which brings the system back to equilibrium. The ECM thus allows for separate estimation of long-term and short-term 
relationships among nonstationary cointegrated variables, provided that such relationships are not spurious and are statistically significant. The cointegrating vector is the set of parameter estimates associated with the long-term component (ECT).

To estimate Equation (3) consistently in light of the aforementioned econometric theory, for each dataset all the variables have been combined, looking for those combinations with one and only one cointegrating vector, according to the Johansen cointegration test. The econometric package EViews 6 provided the automatic selection of lags for this test under five different assumptions concerning the functional form of data and the cointegrating equation (CE):

1. No trend in data, no intercept and trend in the $\mathrm{CE}$

2. No trend in data, intercept and no trend in the CE

3. Linear trend in data, no intercept and trend in the $\mathrm{CE}$

4. Linear trend in data, intercept and trend in the CE

5. Quadratic trend in data, intercept and trend in the CE

Those combinations of variables showing one and only one cointegrating vector, under one or more of the aforementioned assumptions, were tested for estimating an ECM. In doing so, all the necessary restrictions (number of lags for each variable and functional form) were adopted for each selected combination of variables to ensure one cointegrating vector only.

Note that such combinations of variables satisfy only the econometric conditions for the consistent estimation of long-term relationships among variables; in addition, theoretical requirements regarding the significance and sign of parameter estimates have to be fulfilled.

\section{Results}

Before showing the econometric results of the ECM estimation, it is useful to recall the necessary conditions that parameter estimates of each variable should satisfy according to economic theory and model prescriptions to test conclusively the competitive behaviour along the food chain:

- According to economic theory, producer price and marketing cost parameters should always be positive and significantly different from zero $\left(\beta_{1}>0 ; \beta_{2}>0\right)$; one could argue that this may not be the case in the short term (because of asymmetric price transmission), however, ECM estimation describes the long-term relationships among variables;

- To infer perfect competition along the food chain, supply and demand shifter parameters have to simultaneously not be significantly different from zero $\left(\beta_{3}=\beta_{4}=0\right)$;

- To infer market power exertion along the food chain, the demand shifter parameter has to be positive and significantly different from zero, while simultaneously the supply shifter parameter has to be negative and significantly different from zero $\left(\beta_{3}>0 ; \beta_{4}<0\right)$.

These conditions have to be met to obtain unambiguous conclusions in performing market power tests and are then compared to the sign and significance of the explanatory variable parameter estimates in the cointegrating vector. Such parameters describe the long-term equilibrium relationships between the dependent variable (retail milk price) and each explanatory variable in the theoretical model. Among all the combinations of I(1) variables showing one cointegrating vector, where possible, those with parameters that are statistically significant and signed according to model prescriptions will be presented, or at least those closest to such requirements.

For algebraic reasons, the $t$-values of explanatory variables have been multiplied by -1 to render the cointegrating vector comparable to the parameters in Equation (3), normalizing with respect to the dependent variable.

Table 2 reports the estimation results for dataset A (January 1996 to October 2003) in which all the combinations presented are consistent with economic theory, indicating that consumer price is linked by a significantly positive relationship to producer price and marketing costs (any other result would be meaningless in the long term). The food demand shifter parameter is not significantly different 
from zero in the first four combinations, whereas it is significantly negative in the last one, failing to satisfy the model prescriptions. The farm supply shifter is always negative and significant, pointing to market power exertion during the period considered; however, this is not sufficient to reach such a conclusion as the same coherence is simultaneously needed for both of the shifter parameters.

Table 2. Dataset A (January 1996-October 2003) ECM cointegrating vectors parameters [ $t$ values] normalized with respect to retail price (91 observations, two lags in variables).

\begin{tabular}{|c|c|c|c|c|c|c|c|}
\hline \multicolumn{8}{|c|}{ Expected signs with market power exertion } \\
\hline \multirow{2}{*}{\multicolumn{8}{|c|}{$\begin{array}{l}>0 \\
\text { Expected signs with perfect competition }\end{array}$}} \\
\hline & & & & & & & \\
\hline & $>0$ & $>0$ & \multicolumn{2}{|c|}{ not significant $\neq 0$} & \multicolumn{3}{|c|}{ not significant $\neq 0$} \\
\hline \multirow{2}{*}{$\begin{array}{l}\text { Assumption on } \\
\text { Cointegrating } \\
\text { Equation }\end{array}$} & \multirow{2}{*}{$\begin{array}{l}\text { Producer } \\
\text { Price } \\
\text { PMA }\end{array}$} & \multirow{2}{*}{$\begin{array}{c}\text { Marketing } \\
\text { Costs } \\
\text { MB }\end{array}$} & \multicolumn{2}{|c|}{ Demand Shifter } & \multicolumn{2}{|c|}{ Supply Shifter } & \multirow{2}{*}{$\begin{array}{c}\text { ECT of } \\
\text { Dependent } \\
\text { Variable }\end{array}$} \\
\hline & & & & & SS2 & SS3 & \\
\hline \multirow[t]{2}{*}{5} & 2.226 & 10.432 & DS2 & 2.936 & -5.242 & & 0.007 \\
\hline & [4.915] & [4.524] & & [0.811] & {$[-3.55]$} & - & [2.655] \\
\hline \multirow[t]{2}{*}{5} & 3.479 & 16.273 & DS1 & 1.414 & -7.734 & & 0.004 \\
\hline & [5.1667] & [4.655] & & [0.268] & {$[-3.511]$} & - & [2.588] \\
\hline \multirow[t]{2}{*}{4} & 12.567 & 64.761 & DS2 & 2.429 & -31.254 & & 0.001 \\
\hline & [4.476] & [4.530] & & [0.108] & {$[-3.411]$} & - & [3.002] \\
\hline \multirow[t]{2}{*}{4} & 5.554 & 26.914 & DS1 & 0.519 & -12.626 & & 0.003 \\
\hline & [5.03] & [4.69] & & [0.060] & {$[-3.494]$} & - & [2.706] \\
\hline \multirow[t]{2}{*}{1} & 2.147 & 3.593 & DS3 & -2.089 & & -2.509 & 0.007 \\
\hline & [4.039] & [3.697] & & {$[-2.270]$} & - & {$[-3.311]$} & [3.276] \\
\hline \multicolumn{8}{|c|}{$t$ distribution critical values with 87 degree of freedom } \\
\hline $1 \%$ & & \pm 2.371 & & & & & \\
\hline $5 \%$ & & \pm 1.663 & & & & & \\
\hline $10 \%$ & & \pm 1.2915 & & & & & \\
\hline
\end{tabular}

Given the available data, for the period covered by dataset A, the test fails to detect any form of imperfect competition along the fluid milk supply chain. Note that this does not point to perfect competition in the marketing chain in the same period as the necessary conditions (non-significant effects of both of the shifters on consumer price) are not achieved. In other words, the empirical results do not provide any clear evidence of the conduct (perfect or imperfect competition) in the Italian fluid milk chain over the period January 1996 to October 2003. This outcome may represent a weak point for the proposed methodology as it was not able to provide conclusive results. On the other hand, this (lack of) conclusion is compatible with the conclusions of the market monitoring action carried out by the NCA between 1992 and 1994, which did not find enough evidence of anticompetitive behaviours along the milk supply chain to justify an intervention.

Table 3 shows the $t$-values of the parameter estimates for dataset B (January 2000 to October 2008). It is worth remembering that combinations of variables that are apparently identical differ for assumptions regarding data and the functional form of the cointegrating vector.

In the first four combinations, producer price is proxied by the import milk price; in such cases, all the parameters are highly significant (at 1\%) and signed as suggested by economic theory and the theoretical model, detecting market power exertion along the supply chain during the period examined. Similar indications come from the last five combinations of variables using the Ismea producer milk price index (PMB) and the Istat producer animal price index (PAPB) as proxies. In the regression including the $\mathrm{PMB}$, all parameters are significant at 1\% except for MA1 (marketing costs) at $2.5 \%$ significance. Regressions using the PAPB still show significant and "well-signed" parameters, although the significance of marketing costs falls to $5 \%$.

In the complex four, over nine presented combinations indicate with no doubt (1\% significance) that over the period January 2000 to October 2008 the Italian fluid milk supply chain was imperfectly competitive in one or more of the vertically related markets. However, as mentioned earlier, with the theoretical model adopted, it is not possible to identify at what level, on which side (demand or supply) or to what extent market power was exerted. 
Table 3. Dataset B (January 2000-October 2008). ECM cointegrating vectors parameters [ $t$ values] normalized with respect to retail.

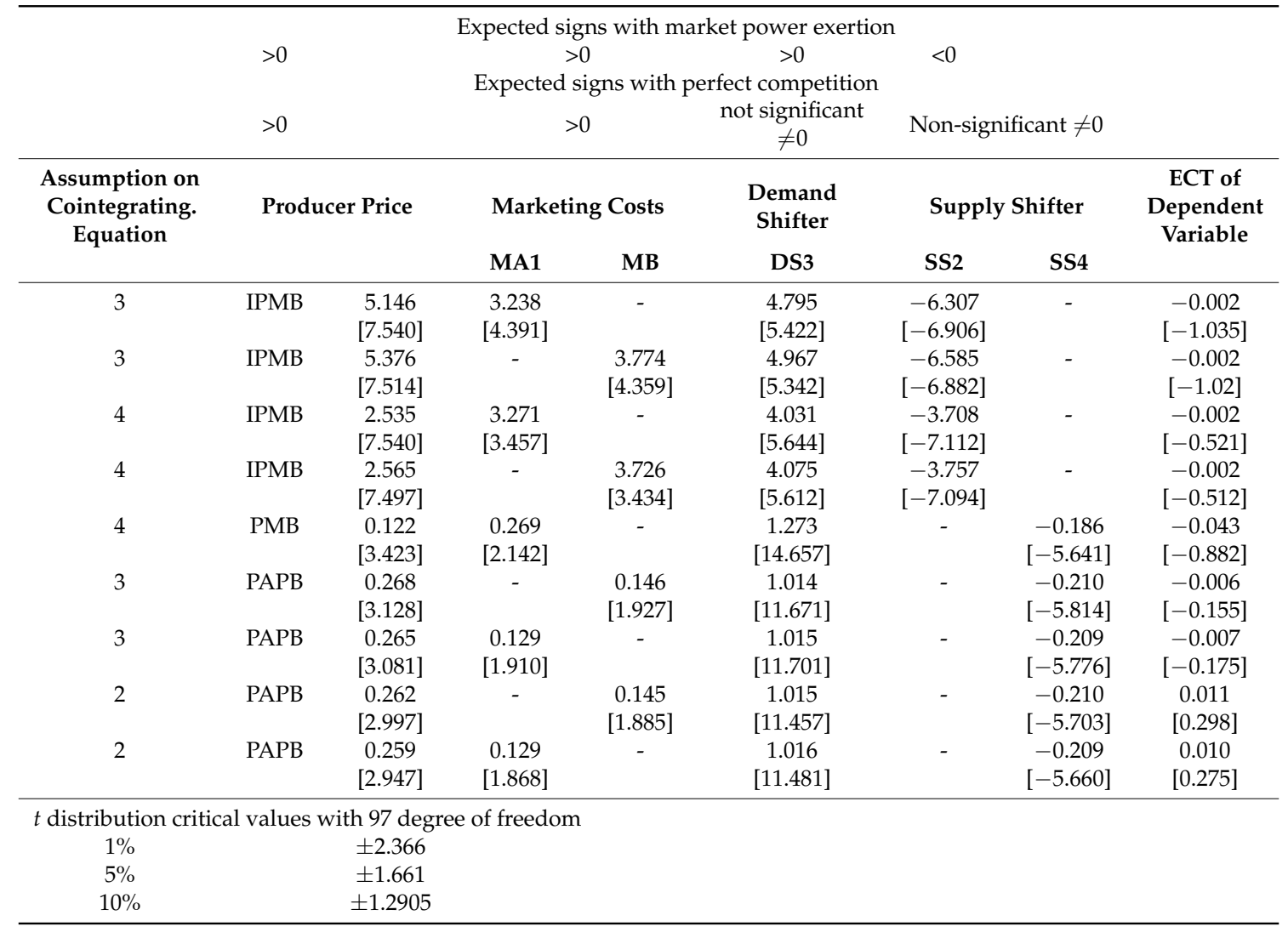

Table 4 reports the $t$-values of cointegrating vectors obtained from dataset AB (January 1996 to October 2008), built up using a longer time series obtained by rebasing the original ones. The first unexpected result is shown in the first four rows of the table, with the import price indices for milk (IPMA and IPMB) being used as proxies of producer price. ECM estimation using such variables yields the best results in terms of the sign and significance of long-term parameter estimates, thus indicating market power exertion.

However, these variables should have been excluded from the set of time series used for empirical estimation as they resulted in being stationary in level and first difference, $\mathrm{I}(0)$, according to three different tests (ADF, PP and KPSS). Following relevant econometric theory, a cointegrating relationship can be sought only among series sharing the same order of integration and, therefore, the results obtained using stationary variables may be spurious

Note that the shorter and non-rescaled portions of IPMA and IPMB used in datasets A and B are $\mathrm{I}(1)$ and it is thus plausible to infer some kind of modification in time series patterns induced by the rebasing procedures. In any case, the ECM estimations using IPMA and IPMB are probably spurious, and conclusions regarding market power detection based on them cannot be considered reliable. Therefore, the results including IPMA and IPMB variables have been presented only to provide a more complete picture of outcomes deriving from all the possible combinations of variables.

Among the other I(1) variables, however, there are combinations providing conclusive results according to model prescriptions: The two cointegrating vectors with PAP1A and PAP1B (index of animal product prices) as proxies of producer price yield parameter estimates that fulfil the necessary conditions for the presence of imperfect competition along the food chain. All the other combinations, with PM2A, PM3A PM4A and PM5A for producer price, have marketing cost parameters not significantly different from zero. As this result is not plausible based on economic theory, no clear conclusions can be drawn from these combinations of variables. In complex, only two cointegrating 
vectors have parameter estimates that are consistent, in sign and significance, with evidence of anticompetitive behaviour at some stages of the fluid milk supply chain over the period January 1996 to October 2008.

Table 4. Dataset AB (January 1996-October 2008) ECM cointegrating vectors parameters [ $t$ values] normalized with respect to retail price (149 observations. 4 lags in variables).

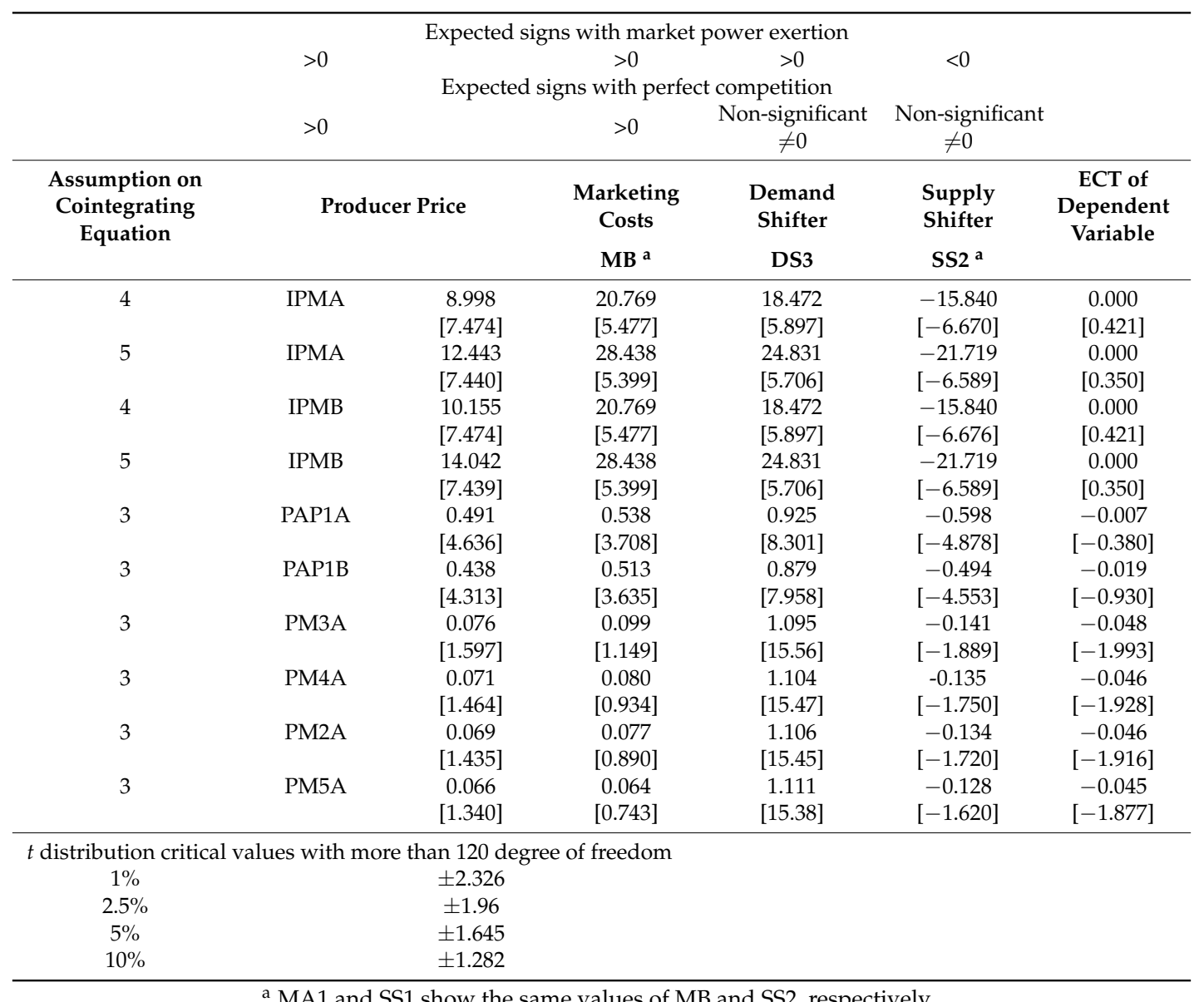

${ }^{a}$ MA1 and SS1 show the same values of MB and SS2, respectively.

To sum up, the empirical analysis detected market power exertion along the Italian fluid milk supply chain in two of the three periods examined (January 2000 to October 2008 and January 1996 to October 2008), while no conclusive results may be drawn about the degree of competition along the fluid milk chain over the period 1996-2003. In order to avoid confusion in the reader, it is worth remembering that Tables 3 and 4 report both conclusive evidence of market power exertion and non-conclusive results. The co-existence of such outcomes does not represent a contradiction, as the absence of clear evidence of market power (that is, the rejection of the null hypothesis reported in Equation (5)) does not imply perfect competition. The strategy of using more time series as proxies of each variable was necessary to ensure a sufficient combination of variables with the same order of integration, one cointegrating vector and parameter estimates with sign and significance in line with the theoretical model prescription.

\section{Discussion and Concluding Comments}

This paper aims to make an empirical contribution to competition analysis of the food supply chain, applying a theoretical framework that yields conclusive results on market power exertion using easily available data. For this reason, such an approach may be used as a "first pass" test [11] to check for the presence of imperfect competition along the supply chain, before applying more complex 
and data-intensive methods to measure the extent of market power in each vertically related market. Such a combination and integration of methods can be a useful tool for improving the efficiency of competition policy analysis, as suggested by Digal and Ahmadi-Esfahani [5] and, more recently, by Lloyd [6]. In this context, the aim of this contribution is twofold: firstly, to compare empirical findings on market power exertion on the Italian fluid milk supply chain with the conclusion of Antitrust investigation on the same domain, carried out over a previous period. Secondly, in doing so, to uncover empirical and theoretical issues emerging during the process to provide useful hints and suggestions for model improvement and future research.

The imperfect competition test has pointed out the exercise of market power at some stage of the Italian fluid milk supply chain over the period 1996-2008, although no conclusions can be drawn for the period 1996-2003. This evidence is consistent with the results of Madau et al. [57] that found evidence of imperfect competition in the same food chain over the period 2000-2013. It should be noted that the absence of clear evidence of market power does not imply perfect competition as in the latter case neither demand nor supply shifters should affect the retail price. Such lack of clarity in the findings is, however, compatible with the conclusions of the 1992-1994 market monitoring action by the Italian NCA.

From a methodological viewpoint, this empirical exercise has provided evidence of some peculiarities and limitations of the market power test implemented. Although this approach can yield conclusive indications regarding the conduct of food supply chains (whereas APT studies cannot), in some cases it may not be possible to obtain unambiguous results because of the combination of econometric and model prescription requirements. From the econometric side, only those combinations of variables with the same order of integration and one, and only one, cointegrating vector can be used for estimating the ECM, whereas economic theory considers plausible only those results in which producer price and marketing cost have a positive effect on the retail price. However, the fulfilment of the aforementioned necessary conditions does not ensure the conclusiveness of the market power test as model prescriptions point to market power along the food chain only with positive demand and (simultaneously) negative supply shifters or to perfect competition when both of the shifters are (simultaneously) not statistically significant in their parameter estimates. Such combinations of conditions suggest the use of more time series approximating each variable of the model to obtain more combinations of variables that in turn increase the probability of attaining a clear result (market power exertion or perfect competition along the food chain). This is the strategy followed in this paper, but unfortunately it may make the implementation of the market power test more complex, harming, in part, one of its advantages over the NEIO structural models. In this regard, a viable alternative, and/or a useful complemental fool may be represented by the empirical approach developed by Grau and Hockmann, [46].

Along with such caveats, the empirical application of the model suggests many aspects for its improvement. A crucial point pertains to the validation of the theoretical model employed in the analysis; indeed, the possible empirical outcomes (presence/absence of market power or inconclusive results) neither contradict nor confirm the validity of the underlying theoretical framework, as counterfactual evidence is missing. There are two main ways of obtaining such evidence: setting up Monte Carlo simulations or analysing each stage (market) of the supply chain using structural models. The first approach has also been used to validate some NEIO models [66,67] and would provide more general results as they allow the simulation of vertically related markets (having different a priori determined levels of conduct at each stage) on which to perform the market power test. Such simulated supply chains would yield data (prices, marketing costs and shifters) used in the market power test. The model would be validated if the market power test yielded results in line with the conduct imposed in the simulated supply chain examined. The second way would consist of analysing the same supply chain over the same time span with a set of NEIO models and the market power test, and then comparing the estimations yielded by the former to the results of the latter. In this case, clearly the validation would be confined to the supply chain analysed and a certain amount of effort 
would be required to examine oligopolisitic power (on the supply side) and oligopsonistic power (on the demand side) in each stage of the food chain examined with a battery of subsequent structural models. The latter aspect could be made simpler and more flexible in part by using a multi-stage structural model (such as in Moro et al. [45]). Another aspect subject to improvement concerns variable choice: Where possible, homogeneity in data sources (and then in meta-data) would be desirable, a condition that is not met in this study (different sources of producer price and retail price) and that, in general, is out of the researcher's control when using publicly-available datasets. Using data obtained through different methodologies may result in a sort of within-variable error that in turn reduces the statistical significant of ECM estimates. Estimation results may also be harmed by potentially omitted variable biases in marketing costs and demand and supply shifters. Using a single proxy for these model variables may be misleading (as the supply shifter is a producer price index it is less affected by such criticism.) as such a proxy cannot capture their true effect on retail prices. Using composite indices may address this issue: For instance a "weighted marketing cost index" could account for all input costs (not only wages) in the food chain, whereas a "demand shifter index" may include more variables affecting product demand and agricultural policy effects may be plugged into a "supply shifter index". It should be noted that addressing such data issues may improve the efficiency of the market power test, thus reducing its main limitation.

A further suggestion for model improvement may be undertaken on the theoretical side, relaxing the fixed proportion technology assumption (input-output coefficient $=1$ ) while retaining the empirical testing framework. Such relaxation is necessary to apply the market power test for supply chains with different technological conditions and more importantly, to use it at a more aggregated level, looking for market power exertion at the agrifood system level and then for macro groups of food chains (animal products, crop products) following a "general to particular" approach.

Supplementary Materials: The following are available online at http:/ /www.mdpi.com/2077-0472/8/12/191/s1. Table S1: Dataset A: Unit Root test (variables in level), 1996.01-2003.10, Table S2: Dataset A: Unit Root test (variables in first difference), 1996.01-2003.10, Table S3: Dataset B: Unit Root test (variables in level), 2000.01-2008.10, Table S4: Dataset B: Unit Root test (variables in first difference), 2000.01-2008.10, Table S5: Dataset AB: Unit Root test (variables in level), 1996.01-2008.10, Table S6: Dataset AB: Unit Root test (variables in first difference), 1996.01-2008.10.

Funding: This research received no external funding.

Acknowledgments: The Author is grateful to Roberto Pretolani, Lucia Baldi and Marc F. Bellemare for helpful comments.

Conflicts of Interest: The author declares no conflict of interest. 


\section{Appendix A}

Table A1. Variables included in dataset A and descriptive statistics (common sample January 1996-October 2003, 94 observations).

\begin{tabular}{|c|c|c|c|c|c|c|c|c|c|}
\hline Variable & Abbrev & Data Description & Mean & Median & Max & Min & Std. Dev. & Skew & Kurt \\
\hline Retail Milk price & RM1 & Consumer Price Index: milk & 111.505 & 108.000 & 124.100 & 102.400 & 6.455 & 0.707 & 1.982 \\
\hline Produc. Milk Price & PMA & Producer Price Index: cow milk & 99.312 & 98.210 & 110.520 & 92.100 & 5.241 & 0.592 & 2.598 \\
\hline Produc. Anim Price & PAPA & Producer price Index: animal products & 104.144 & 104.900 & 111.900 & 93.900 & 3.865 & -0.324 & 2.896 \\
\hline Import Produc. Milk & IPMA & Index of milk import price from EU 25 & 109.125 & 107.949 & 122.363 & 100.387 & 5.394 & 0.662 & 2.616 \\
\hline Marketing Shifter & MA1 & Index of wages, dairy processing sector & 109.694 & 109.800 & 120.524 & 100.000 & 5.437 & 0.048 & 2.223 \\
\hline Marketing Shifter & MB & Index of wages, dairy processing sector & 98.312 & 98.400 & 108.000 & 89.600 & 4.888 & 0.044 & 2.210 \\
\hline Demand Shifter & DS1 & Consumer Price Index: general index & 112.004 & 111.050 & 122.700 & 102.500 & 5.817 & 0.252 & 1.844 \\
\hline Demand Shifter & DS2 & Consumer Price Ind: general index-no tobacco & 111.946 & 110.950 & 122.600 & 102.400 & 5.842 & 0.253 & 1.822 \\
\hline Demand Shifter & DS3 & Consumer Price Index: food, wines and spirits & 108.911 & 106.250 & 121.300 & 102.200 & 5.447 & 0.781 & 2.167 \\
\hline Supply Shifter & SS1 & producer price index for dairy farms & 103.322 & 102.915 & 109.345 & 98.220 & 2.949 & 0.254 & 1.741 \\
\hline Supply Shifter & SS2 & producer price index for dairy farms & 106.757 & 106.336 & 112.981 & 101.485 & 3.047 & 0.254 & 1.741 \\
\hline Supply Shifter & SS3 & producer price index for dairy farms & 97.629 & 98.245 & 104.590 & 90.410 & 3.014 & -0.354 & 2.822 \\
\hline
\end{tabular}

Table A2. Variables included in dataset B and descriptive statistics (common sample January 2000-October 2008, 106 observations).

\begin{tabular}{|c|c|c|c|c|c|c|c|c|c|}
\hline Variable & Abbrev & Data Description & Mean & Median & Max & Min & Std. Dev. & Skew & Kurt \\
\hline Retail Milk price & RM1 & Consumer Price Index: milk & 124.023 & 124.750 & 144.100 & 108.000 & 8.600 & 0.357 & 3.254 \\
\hline Produc. Milk Price & PMB & Producer Price Index: cow milk & 102.371 & 99.198 & 124.008 & 93.747 & 6.926 & 1.292 & 4.109 \\
\hline Produc. Anim Price & PAPB & Producer price Index - animal products & 103.786 & 102.400 & 116.700 & 98.500 & 4.408 & 1.571 & 4.711 \\
\hline Import Produc. Milk & IPMB & Index of milk import price from EU 25 & 95.904 & 94.471 & 114.840 & 86.361 & 6.956 & 0.654 & 2.539 \\
\hline Marketing Shifter & MA1 & Index of wages, dairy processing sector & 123.411 & 123.872 & 140.612 & 109.800 & 9.501 & 0.233 & 1.811 \\
\hline Marketing Shifter & MB & Index of wages, dairy processing sector & 110.601 & 111.000 & 126.000 & 98.400 & 8.500 & 0.234 & 1.815 \\
\hline Demand Shifter & DS1 & Consumer Price Index: general index & 124.196 & 124.700 & 138.000 & 111.300 & 7.321 & 0.026 & 1.978 \\
\hline Demand Shifter & DS2 & Consumer Price Ind: general index-no tobacco & 123.945 & 124.500 & 137.400 & 111.200 & 7.113 & 0.011 & 2.016 \\
\hline Demand Shifter & DS3 & Consumer Price Index: food, wines and spirits & 120.397 & 121.900 & 136.300 & 106.200 & 7.636 & -0.001 & 2.486 \\
\hline Supply Shifter & SS1 & producer price index for dairy farms & 112.957 & 111.361 & 133.712 & 100.826 & 8.665 & 1.033 & 3.167 \\
\hline Supply Shifter & SS2 & producer price index for dairy farms & 116.713 & 115.063 & 138.158 & 104.179 & 8.953 & 1.033 & 3.167 \\
\hline Supply Shifter & SS4 & producer price index for dairy farms & 107.909 & 103.352 & 135.272 & 96.857 & 10.188 & 1.363 & 3.808 \\
\hline
\end{tabular}


Table A3. Variables included in Dataset AB and descriptive statistics (common sample January 1996-October 2008, 154 observations).

\begin{tabular}{|c|c|c|c|c|c|c|c|c|c|}
\hline Variable & Abbrev & Data description & Mean & Median & Max & Min & Std. Dev. & Skew & Kurt \\
\hline Retail Milk price & RM1 & Consumer Price Index: milk & 118.526 & 119.250 & 144.100 & 102.400 & 10.879 & 0.412 & 2.341 \\
\hline Produc. Milk Price & PM1A & Producer Price Index: cow milk—rescaled & 98.707 & 95.730 & 118.742 & 89.766 & 6.552 & 0.986 & 3.291 \\
\hline Produc. Milk Price & PM2A & Producer Price Index: cow milk—rescaled & 98.820 & 95.730 & 119.095 & 90.033 & 6.549 & 1.023 & 3.389 \\
\hline Produc. Milk Price & PM3A & Producer Price Index: cow milk—rescaled & 98.254 & 95.230 & 117.331 & 88.699 & 6.596 & 0.829 & 2.933 \\
\hline Produc. Milk Price & PM4A & Producer Price Index: cow milk—rescaled & 98.725 & 95.730 & 118.797 & 89.808 & 6.552 & 0.992 & 3.306 \\
\hline Produc. Milk Price & PM5A & Producer Price Index: cow milk—rescaled & 99.133 & 95.811 & 120.070 & 90.770 & 6.556 & 1.122 & 3.670 \\
\hline Produc. Milk Price & PM1B & Producer Price Index: cow milk—rescaled & 103.084 & 99.796 & 124.008 & 93.747 & 6.940 & 0.954 & 3.139 \\
\hline Produc. Milk Price & PM2B & Producer Price Index: cow milk—rescaled & 102.987 & 99.796 & 124.008 & 93.747 & 6.913 & 0.964 & 3.185 \\
\hline Produc. Milk Price & РМ3B & Producer Price Index: cow milk—rescaled & 103.476 & 100.120 & 124.008 & 93.747 & 7.077 & 0.911 & 2.965 \\
\hline Produc. Milk Price & PM4B & Producer Price Index: cow milk—rescaled & 103.069 & 99.796 & 124.008 & 93.747 & 6.935 & 0.956 & 3.146 \\
\hline Produc. Milk Price & PM5B & Producer Price Index: cow milk—rescaled & 102.723 & 99.796 & 124.008 & 93.747 & 6.855 & 0.988 & 3.317 \\
\hline Produc. Anim Price & PAP1A & Produc. Pric. Ind.: animal products—rebas & 105.280 & 104.702 & 119.557 & 93.900 & 4.817 & 0.901 & 4.367 \\
\hline Produc. Anim Price & PAP1B & Produc. price Index: anim products, rebas & 103.027 & 102.495 & 116.700 & 91.656 & 4.682 & 0.762 & 4.243 \\
\hline Import Produc. Milk & IPMA & Index of milk import price from EU 25 & 107.960 & 106.861 & 129.599 & 97.461 & 6.840 & 0.783 & 3.219 \\
\hline Import Produc. Milk & IPMB & Index of milk import price from EU 25 & 95.665 & 94.691 & 114.840 & 86.361 & 6.061 & 0.783 & 3.219 \\
\hline Marketing Shifter & MA1 & Index of wages, dairy processing sector & 117.786 & 115.250 & 140.612 & 100.000 & 11.632 & 0.376 & 1.979 \\
\hline Marketing Shifter & MB & Index of wages, dairy processing sector & 105.557 & 103.350 & 126.000 & 89.600 & 10.421 & 0.373 & 1.980 \\
\hline Demand Shifter & DS1 & Consumer Price Index: general index & 118.864 & 118.650 & 138.000 & 102.500 & 10.083 & 0.125 & 1.784 \\
\hline Demand Shifter & DS2 & Consumer Price Ind: general index-no tobacco & 118.664 & 118.700 & 137.400 & 102.400 & 9.919 & 0.101 & 1.780 \\
\hline Demand Shifter & DS3 & Consumer Price Index: food, wines and spirits & 115.478 & 115.900 & 136.300 & 102.200 & 9.700 & 0.287 & 1.879 \\
\hline Supply Shifter & SS1 & producer price index for dairy farms & 109.210 & 106.583 & 133.712 & 98.220 & 9.123 & 1.169 & 3.656 \\
\hline Supply Shifter & SS2 & producer price index for dairy farms & 112.841 & 110.127 & 138.158 & 101.485 & 9.427 & 1.169 & 3.656 \\
\hline
\end{tabular}




\section{Appendix B. Derivation of the Theoretical Model}

Here is shown the full derivation of the theoretical model presented in Section 3.

Let us take a food supply chain that faces, on the consumer side, an inverse demand function:

$$
x=D\left(P_{x}, N\right)
$$

where $x$ is the quantity of food products sold, $P_{x}$ is the consumer price and $N$ is an exogenous food demand shifter. At the first stage of the chain, the raw agricultural product is sold according to a supply function:

$$
P a=h(a, W)
$$

where $P_{a}$ is the farm gate price of the raw agricultural product, $a$ is the quantity sold and $W$ is an exogenous shifter of the farm supply function. As previously mentioned, the intermediate food processing and retailing stage is seen as the most likely source of market power and thus its behaviour is explicitly modelled using a profit function of the $i$-th firm:

$$
\pi_{i}=P_{x}(x) x_{i}-P_{a}(a) a_{i}-C_{i}\left(x_{i}\right)
$$

where $\pi_{i}, x_{i}$ and $a_{i}$ are, respectively, profit, quantity of food sold and quantity of raw agricultural product bought by the $i$-th firm and $C_{i}$ are costs not associated with the agricultural product. Furthermore, for this stage of the food chain, a constant return to scale and fixed proportion technology are assumed; the latter assumption is represented by:

$$
x_{i}=\frac{a_{i}}{\rho}
$$

where $\rho$ is an input-output coefficient that equals one. This assumption imposes a limitation on the empirical application of the model. The profit-maximizing first-order conditions for the $i$-th firm are:

$$
P_{x}+x_{i} \frac{\partial P_{x}}{\partial x} \frac{\partial x}{\partial x_{i}}=\frac{\partial C_{i}}{\partial x_{i}}+\rho P_{a}+\rho a_{i} \frac{\partial P_{a}}{\partial a} \frac{\partial a}{\partial a_{i}}
$$

To obtain an explicit solution to (A5) under the previous assumptions, the agricultural supply (A2) and food demand (A1) functions are linearized as follows:

$$
\begin{gathered}
x=D-b P_{x}+c N \\
P a=h+g S
\end{gathered}
$$

in which $S$ is the food product supplied in a country that is in turn composed by:

$$
S=x_{i}+W
$$

where the exogenous shifter $W$ that appears in (A2) is the level of exports. Using (A6)-(A8), the profit-maximizing conditions (A5) can be rewritten allowing for the exertion of oligopolistic and oligopsonistic power by the intermediate stage of the food chain:

$$
P_{x}-\frac{\theta}{b} x=M+P_{a}+\mu g x
$$

with $\theta$ and $\mu$ representing, respectively, oligopolistic and oligopsonistic conduct parameters (See Section 2.2 on new empirical industrial organization (NEIO) structural models for an explanation of conduct parameters.) ranging from 0 (perfect competition) to 1 (monopoly-monopsonistic behaviour), where the former represents the behaviour of the processing-retailing stage in the product (food) market, while the latter embodies its conduct in buying (raw agricultural) factor. When the food 
supply chain is perfectly competitive, both parameters equal 0 , while departures from this benchmark are associated with increasing values up to 1 .

Although these parameters are widely used in the NEIO literature to estimate the extent of imperfect competition, in this context, they are used only as instruments to signal collusive behaviour.

The variable $M$, which appears in Equation (A9), represents all the non-agricultural costs that determine the extent of the marketing margin $\left(P_{x}-P_{a}\right) . M$ thus contains both fixed and variable components:

$$
M=y+z E
$$

where $y$ is a fixed cost component and $z E$ represents variable costs associated with non-agricultural inputs (e.g., labour costs for processing and retailing). The previous Equations (A6), (A7), (A9), and (A10) are employed as a set to represent endogenous variables in the explicit form:

$$
\begin{gathered}
x=\frac{(D-b y-b h)+c N-b z E-b g W}{(1+\theta)+b g(1+\mu)} \\
P_{x}=\frac{D+[(1+\theta)+(b g(1+\mu)] \cdot[(1-b)(y+h+g W)+(1-b z) E+c N]}{(1+\theta)+b g(1+\mu)} \\
M=y+z E P_{a}=\frac{g[(k-b y+c N-b z E]-g\{b-[(1+\theta)+b g(1+\mu)](h+W)\}}{(1+\theta)+b g(1+\mu)}
\end{gathered}
$$

By subtracting Equation (A12) from Equation (A13) and rearranging, it is possible to make explicit the marketing margin $\left(P_{x}-P_{a}\right)$ :

$$
P_{x}-P_{a}=\frac{D\left(\frac{\theta}{b}+g \mu\right)+(1+b g)(y+z E)+\left(\frac{\theta}{b}+g \mu\right) c N-(\theta+b g \mu)(h+g W)}{(1+\theta)+b g(1+\mu)}
$$

Equation (A14) derived here corresponds to Equation (1) presented in Section 3 of the main text.

\section{References}

1. Dobson, P.W.; Clarke, R.; Davies, S.; Waterson, M. Buyer power and its impact on competition in the food retail distribution sector of the European Union. J. Ind. Compet. Trade 2001, 1, 247-281. [CrossRef]

2. Dobson, P.W.; Waterson, M. Retail power: Recent developments and policy implications. Econ. Policy 1999, 28, 133-164. [CrossRef]

3. Dobson, P.W.; Waterson, M.; Davies, S. The patterns and implications of increasing concentration in European food retailing. J. Agric. Econ. 2003, 54, 111-125. [CrossRef]

4. Von Blanckenburg, K.; Geist, A.; Kholodilin, K.A. The influence of collusion on price changes: New evidence from major cartel cases. Ger. Econ. Rev. 2011, 13, 245-256. [CrossRef]

5. Digal, L.N.; Ahmadi-Esfahani, F.Z. Market power analysis in the food industry: A survey of methods. Aust. J. Agric. Resour. Econ. 2002, 46, 559-584. [CrossRef]

6. Lloyd, T. Forty years of price transmission research in the food industry: Insights, challenges and prospects. J. Agric. Econ. 2017, 68, 3-21. [CrossRef]

7. McCorriston, S.; Morgan, C.W.; Rayner, A.J. Processing technology, market power and price transmission. J. Agric. Econ. 1998, 49, 185-201. [CrossRef]

8. McCorriston, S.; Morgan, C.W.; Rayner, A.J. Price transmission: The interaction between market power and returns to scale. Eur. Rev. Agric. Econ. 2001, 28, 143-159. [CrossRef]

9. Lloyd, T.; McCorriston, S.; Morgan, W.; Rayner, A. Food scares, market power and price transmission: The UK BSE crisis. Eur. Rev. Agric. Econ. 2006, 33, 119-147. [CrossRef]

10. Lloyd, T.; McCorriston, S.; Morgan, W.; Rayner, A. Market power in UK food retailing: Theory and evidence from seven product groups. In Proceedings of the 24th IAAE Conference, Gold Coast, Australia, 12-18 August 2006.

11. Lloyd, T.; McCorriston, S.; Morgan, W.; Rayner, A.; Weldegebriel, H. Buyer power in UK food retailing: A 'first-pass' test. J. Agric. Food Ind. Organ. 2009, 7. [CrossRef] 
12. European Commission. A Better Functioning Food Supply Chain in Europe; Communication (2009) 591; European Commission: Brussels, Belgium, 2009.

13. European Commission. Competition in the Food Supply Chain; Accompanying document to the Communication (2009) 591. A better functioning food supply chain in Europe; European Commission: Brussels, Belgium, 2009.

14. AGCM (Autorità Garante della Concorrenza e del Mercato). Chiusura Dell'indagine Conoscitiva nel Settore del Latte (Rif. IC2); AGCM: Rome, Italy, 1994.

15. Meyer, J.; von Cramon-Taubadel, S. Asymmetric price transmission: A survey. J. Agric. Econ. 2004, 55, 581-611. [CrossRef]

16. Perloff, J.M.; Karp, L.S.; Golan, A. Estimating Market Power and Strategies; Cambridge University Press: New York, NY, USA, 2007.

17. Peltzman, S. Prices rise faster than they fall. J. Polit. Econ. 2000, 108, 466-502. [CrossRef]

18. Cacchiarelli, L.; Sorrentino, A. Antitrust intervention and price transmission in pasta supply chain. Agric. Food Econ. 2015, 4, 2. [CrossRef]

19. Antonioli, F.; Ben Kaabia, M.; Arfini, F.; Gil, J.M. Price transmission dynamics for quality-certified food products: A comparison between conventional and organic fluid milk in Italy. Agribusiness 2018. [CrossRef]

20. Gardner, B.L. The farm-retail price spread in a competitive food industry. Am. J. Agric. Econ. 1975, 76, 641-646. [CrossRef]

21. Wohlgenant, M.K. Marketing margins: Empirical analysis. In Handbook of Agricultural Economics; Gardner, B.L., Rausser, G.C., Eds.; North-Holland: Amsterdam, The Netherlands, 2001.

22. Vavra, P.; Goodwin, B.K. Analysis of Price Transmission along the Food Chain; OECD Food Agriculture and Fisheries Working Papers No. 3; OECD Publishing: Paris, France, 2005.

23. Kinnucan, H.W.; Forker, O.D. Asymmetry in farm-retail price transmission for major dairy products. Am. J. Agric. Econ. 1987, 69, 307-328. [CrossRef]

24. Bernard, J.C.; Schertz Willet, L. Asymmetric price relationships in the U.S. broiler industry. J. Agric. Appl. Econ. 1996, 28, 279-289. [CrossRef]

25. Miller, D.J.; Hayenga, M.L. Price cycles and asymmetric price transmission in the U.S. pork market. Am. J. Agric. Econ. 2001, 83, 551-562. [CrossRef]

26. Ben-Kaabia, M.; Gil, J.M. Asymmetric price transmission in the Spanish lamb sector. Eur. Rev. Agric. Econ. 2007, 34, 53-80. [CrossRef]

27. Cacchiarelli, L.; Sorrentino, A. Market power in food supply chain: Evidence from Italian pasta chain. $\mathrm{Br}$. Food J. 2018, 120, 2129-2141. [CrossRef]

28. Hallam, D.; Rapsomanikis, G. Transmission of Price Signals and the Distribution of Revenues along the Commodity Supply Chains: Review and Applications; Food and Agriculture Organization of the United Nations, Commodities and Trade Division: Rome, Italy, 2006.

29. Awokuse, T.O.; Wang, X. Threshold effects and asymmetric price adjustment in U.S. dairy markets. Can. J. Agric. Econ. 2009, 57, 269-286. [CrossRef]

30. Clarke, R.; Davies, S.W. Market structure and price-cost margins. Economica 1982, 49, 277-287. [CrossRef]

31. Schmalensee, R. Inter-industry studies of structure and performance. In Handbook of Industrial Organization; Schmalensee, R., Willig, R., Eds.; Elsevier: Amsterdam, The Netherlands, 1989; pp. 952-1009.

32. Sheldon, I.; Sperling, R. Estimating the extent of imperfect competition in the food industry: What have we learned? J. Agric. Econ. 2003, 54, 89-109. [CrossRef]

33. Bakucs, Z.; Fałkowski, J.; Fertő, I. Does market structure influence price transmission in the agro-food sector? A meta-analysis perspective. J. Agric. Econ. 2014, 65, 1-25. [CrossRef]

34. Von Cramon-Taubadel, S. Estimating asymmetric price transmission with error correction representation: An application to German pork market. Eur. Rev. Agric. Econ. 1998, 25, 1-18. [CrossRef]

35. Weldegebriel, H.T. Imperfect price transmission: Is market power really to blame? J. Agric. Econ. 2004, 55, 101-114. [CrossRef]

36. Ward, R.W. Asymmetry in retail, wholesale and shipping point pricing for fresh vegetables. Am. J. Agric. Econ. 1982, 62, 205-212. [CrossRef]

37. Bailey, D.; Brorsen, B.W. Price asymmetry in spatial fed cattle markets. West. J. Agric. Econ. 1989, 14, $246-252$.

38. Dutta, S.; Bergen, M.; Levy, D.; Venable, R. Menu costs, posted prices, and multiproduct retailers. J. Money Credit Bank. 1999, 31, 683-703. [CrossRef] 
39. Levy, D.; Bergen, M.; Dutta, S.; Venable, R. The magnitude of menu costs: Direct evidence from large U.S. supermarket chains. Q. J. Econ. 1997, 112, 791-825. [CrossRef]

40. Blinder, A.S. Inventories and sticky prices: More on the microfoundation of macroeconomics. Am. Econ. Rev. 1982, 72, 334-348.

41. Ball, L.; Mankiw, N.G. Asymmetric price adjustment and economic fluctuations. Econ. J. 1994, 104, $247-261$. [CrossRef]

42. Rezitis, A.N.; Pachis, D.N. Price transmission along the Greek food supply chain in a dynamic panel framework: Empirical evidence from the implementation of decoupling. Int. J. Comput. Econ. Econom. 2018, 8, 18-40. [CrossRef]

43. Cacchiarelli, L.; Lass, D.; Sorrentino, A. CAP reform and price transmission in the Italian pasta chain. Agribusiness 2016, 32, 482-497. [CrossRef]

44. Sexton, R.J.; Zhang, M. An assessment of the impact of food industry market power on U.S. consumers. Agribusiness 2001, 17, 59-79. [CrossRef]

45. Moro, D.; Sckokai, P.; Veneziani, M. Multi-stage market power in the Italian fresh meat industry. In Proceedings of the AAEA Meeting, Seattle, WA, USA, 12-14 August 2012; Available online: http:/ / ageconsearch.umn.edu/bitstream/125065/2/Moro\%20Sckokai\%20Veneziani\%20\%282012\%29\% 20Multi-stage\%20Market\%20Power\%20in\%20the\%20Italian\%20Fresh\%20Meat\%20Industry.pdf (accessed on 12 March 2015).

46. Grau, A.; Hockmann, H. Market power in the German dairy value chain. Agribusiness 2018, 34, 93-111. [CrossRef]

47. Corts, K.S. Conduct parameters and the measurement of market power. J. Econom. 1999, 88, $227-250$. [CrossRef]

48. Holloway, G.J. The farm-retail price spread in an imperfectly competitive food industry. Am. J. Agric. Econ. 1991, 73, 979-999. [CrossRef]

49. Fulton, M.; Tang, Y. Testing the competitiveness of a multistage food marketing system: The Canadian chicken industry. Can. J. Agric. Econ. 1999, 47, 225-250. [CrossRef]

50. Wohlgenant, M.K. Demand for farm output in a complete system of demand equations. Am. J. Agric. Econ. 1989, 72, 241-252. [CrossRef]

51. Fałkowski, J. Price transmission and market power in a transition context: Evidence from the Polish fluid milk sector. Post-Communist Econ. 2010, 22, 513-529. [CrossRef]

52. Furesi, R.; Madau, F.A.; Pulina, P. Potere della distribuzione moderna nelle filiere agroalimentari. Il caso dell'olio d'oliva in Italia. Econ. Agro-Alimentare 2013, 1, 123-143. [CrossRef]

53. Niemi, J.; Xing, L. Empirical "first-filter" test for the existence of buyer power in the Finnish food supply chain. Agric. and Food Sci. 2016, 25, 177-186. [CrossRef]

54. Nakajima, T.; Matsui, T.; Sakai, Y.; Yagi, N. Structural changes and imperfect competition in the supply chain of Japanese fisheries product markets. Fish. Sci. 2014, 80, 1337-1345. [CrossRef]

55. Özertan, G.; Saghaian, S.; Tekgüç, H. Market power in the poultry sector in turkey. İBoğaziçi J. Rev. Soc. Econ. Adm. Stud. 2014, 28, 19-32. [CrossRef]

56. Özertan, G.; Saghaian, S.; Tekgüç, H. Dynamics of price transmission and market power in the Turkish beef sector. İktisat İşletme ve Finans 2015, 30, 53-76. [CrossRef]

57. Madau, F.A.; Furesi, R.; Pulina, P. The existence of buyer power in the Italian fresh milk supply chain. Br. Food J. 2016, 118, 70-82. [CrossRef]

58. Kinnucan, H.W.; Tadjion, O. Theoretical restrictions on farm-retail price transmission elasticities: A note. Agribusiness 2014, 30, 278-289. [CrossRef]

59. Harris, R.; Sollis, R. Applied Time Series Modelling and Forecasting; John Wiley and Son: Chichester, UK, 2003.

60. Enders, W. Applied Econometric Time Series; John Wiley and Son: Chichester, UK, 2004.

61. Granger, C.W.J.; Newbold, P. Spurious regressions in econometrics. J. Econom. 1974, 2, 111-120. [CrossRef]

62. Dickey, D.; Fuller, W.A. Distribution of the estimates for autoregressive time series with a unit root. J. Am. Stat. Assoc. 1979, 74, 427-431. [CrossRef]

63. Phillips, P.C.B.; Perron, P. Testing for a unit root in time series regression. Biometrica 1988, 75, 335-446. [CrossRef] 
64. Kwiatkowski, D.; Phillips, P.C.B.; Schmidt, P.; Shin, Y. Testing the null of stationarity against the alternative of unit root: How sure are we that economic time series have a unit root? J. Econom. 1992, 54, 159-178. [CrossRef]

65. Engle, R.F.; Granger, C.W.J. Co-integration and error correction: Representation, estimation and testing. Econometrica 1987, 55, 251-276. [CrossRef]

66. Hyde, C.E.; Perloff, J.M. Can monopsony power be estimated? Am. J. Agric. Econ. 1994, 76, 1151-1155. [CrossRef]

67. Hyde, C.E.; Perloff, J.M. Can market power be estimated? Rev. Ind. Organ. 1995, 10, 465-485. [CrossRef] 